\title{
Effects of Feed and Mating Age on Reproductive Performance in Syrian Hamsters
}

\author{
Masahiro SATOH and Taro OBATA \\ National Institute of Animal Industry, Norinkenkyudanchi, Tsukuba-shi, Ibaraki 305, Japan
}

(Received 5 October 1994/Accepted 4 April 1995)

\begin{abstract}
In order to utilize Syrian hamsters in selection experiments, we investigated desirable conditions of feed and mating age for reproduction in females. Hamsters were subdivided into two groups, raised on pellet feed for herbivores (ZC-2) and breeding (MB-1), respectively. Half of the hamsters in each group were switched to the other feed, respectively, after mating. They were mated at 8 or 12 weeks of age. In the group that has been fed on ZC-2 before mating and MB- 1 after mating, there was significantly more females giving birth and weaning, and exhibited the largest litter size and litter weight at 3 weeks of age $(\mathrm{P}<0.01)$. The hamsters of the groups mated at 12 weeks of age exhibited a higher percentage of females giving birth and litter size and litter weight at birth than those at 8 weeks of age, but that was no significant difference in litter size and litter weight at 3 weeks of age. We conclude that Syrian hamsters raised by fibrous feed before mating gave optimal reproductive performance.-KEY WORDS: conditions of feed, mating age, reproductive performance, Syrian hamsters
\end{abstract}

シリアンハムスターの給与飼料および交配週歯令が繁殖成績に及ぼす影響

佐藤正寛・小畑太郎

農林水産省畜産試験場

シリアンハムスター(以下, ハムスター)は, 一般 に䋐維質飼料の利用性が高いこと $[6,10]$ や妊娠期間 が短く繁殖性に優れること [4] 等から, 近年, 家畜の 実験動物として利用されるようになってきた。また， 家畜のパイロットアニマルとしての選抜育種実験も試 みられている $[1,9]$ 。実験動物を育種実験に用いる場 合, 発育が速く, 産子数, 離乳子数が多く, 離乳率が 高いこと,早熟で早期に繁殖に供することができるこ と, 飼料等の環境条件に対して適応性が高いこと等が 必要条件としてあげられる [3]。特に, 離乳子数が多 いほど選抜差が大きくなり，また早熟性は世代間隔を 短くすることができるため,この2要因は育種実験を 効率的に行う上で実験動物が備えるべき重要な条件で あると考えられる。
本研究はハムス夕一の育成期と繁殖期の飼育飼料お よび交配週齢と, 受胎率や離乳子数などの繁殖成績と の関係を明らかにし、ハムスターの選抜育種に適した 実験条件について検討することを目的とした。

\section{材料および方法}

実験には（財）日本生物科学研究所より購入し，そ の後当研究室において近交系として維持しているCBN 采ハムスター360匹（雄: 120 匹，雌: 240 匹）を用い た。なお，CBN 采は固形飼料 MB-1（飼料成分等は後 述) および水を自由椇取させることによって維持して いる。八ムス夕ーは温度 $21 \pm 11^{\circ} \mathrm{C}$, 湿度約 $55 \%$, 人工 照明 1 日14時間に設定された飼育室で，プラスチッ 
Table 1. Experimental design

\begin{tabular}{cccc}
\hline \multicolumn{2}{c}{ Feed } & $\begin{array}{c}\text { Age of } \\
\text { mating } \\
\text { Before mating }\end{array}$ & $\begin{array}{c}\text { Number of } \\
\text { females }\end{array}$ \\
\hline ZC-2 & ZC-2 & 8 & 30 \\
& & 12 & 30 \\
ZC-2 & MB-1 & 8 & 30 \\
& & 12 & 30 \\
MB-1 & ZC-2 & 8 & 30 \\
& & 12 & 30 \\
MB-1 & MB-1 & 8 & 30 \\
& & 12 & 30 \\
Total & & & 240 \\
\hline
\end{tabular}

Table 3. $x^{2}$-test of the number of dams given birth and weaned young

\begin{tabular}{lccc}
\hline \multirow{2}{*}{ Source } & d.f. & \multicolumn{2}{c}{ No. of dams } \\
\cline { 3 - 4 } & & Birth & Weaning \\
\hline Feed $(\mathrm{F})$ & 3 & $7.76^{+}$ & $7.73^{+}$ \\
Age of dam (A) & 1 & $3.87^{*}$ & 1.85 \\
Interaction $(\mathrm{F} \times \mathrm{A})$ & 3 & 1.12 & 0.92 \\
\hline
\end{tabular}

${ }^{+}: \mathrm{P}<0.10, *: \mathrm{P}<0.05$

Table 2. The number of dams given birth and weaned young

\begin{tabular}{|c|c|c|c|c|c|c|}
\hline \multirow{2}{*}{ Trait } & \multirow{2}{*}{ Age of dam } & \multicolumn{4}{|c|}{ Feed } & \multirow[b]{2}{*}{ Total } \\
\hline & & $\mathrm{ZC} \rightarrow \mathrm{ZC}$ & $\mathrm{ZC} \rightarrow \mathrm{MB}$ & $\mathrm{MB} \rightarrow \mathrm{ZC}$ & $\mathrm{MB} \rightarrow \mathrm{MB}$ & \\
\hline \multirow[t]{3}{*}{ Birth } & 8 weeks & 23 & 28 & 23 & 22 & 96 \\
\hline & 12 weeks & 28 & 29 & 25 & 25 & 107 \\
\hline & Total & 51 & 57 & 48 & 47 & 203 \\
\hline \multirow[t]{3}{*}{ Weaning } & 8 weeks & 23 & 28 & 22 & 22 & 95 \\
\hline & 12 weeks & 27 & 28 & 24 & 24 & 103 \\
\hline & Total & 50 & 56 & 46 & 46 & 198 \\
\hline
\end{tabular}

ク製ケージに床敷としてチップを入れ，5－6匹を雌 雄別に収容した。供試した半数のハムスターには固形 飼料ZC-2（草食動物用: 棇エネルギー $3.99 \mathrm{kcal} / \mathrm{g}$, 代 謝エネルギー $3.59 \mathrm{kcal} / \mathrm{g}$, 水分 $7.0 \%$ ，粗夕、ンパク質 $18.0 \%$, 粗脂肪 $2.5 \%$, 粗䋐維 $8.0 \%$, 粗灰分 $7.0 \%$, 可 溶無窒素物 $53.9 \%$ ), 残りの半数にはMB-1（繁殖用： 総エネルギー $4.28 \mathrm{Kcal} / \mathrm{g}$, 代謝エネルギー $3.85 \mathrm{kcal} / \mathrm{g}$, 水分 $7.0 \%$, 粗タンパク質 $24.5 \%$, 粗脂肪 $4.4 \%$, 粗䋐 維 $3.6 \%$, 粗灰分 $5.5 \%$, 可溶無窒素物 $55.0 \%$ ：いずれ の飼料も径 $12 \mathrm{~mm}$ のハードペレットで, 製造, 資料提 供船橋農場）を 3 週齢より自由椇取させた（以下，育 成期飼料とする)。また，水は自由飲水とした。それ ぞれの飼料で育成したハムスターの半数を 8 週齢で $(8$ 週齢交配区)，また残りの半数を12週齢で（12 週齢交 配区）原則として雄 1 対雌 2 の兄妹交配を行った。交 配期間は最大 16 日間とした。交配時に，ZC-2で㕕成 したハムスターの半数の飼料を MB-1に, MB-1 で育 成したハムスターの半数の飼料を ZC- 2 に切り換えた (以下, 繁殖期飼料とする)。各実験飼料区に用いたハ ムスターの匹数はTable 1のようになる。

交配時に雌の体重を測定し,その後㓐分泌物により 発情日を確認した。妊娠が確認されたハムスターは個 別飼いにして分婏させた。分婏日に雌親の体重, 産子 数, 産子の一腹体重を測定した。その後, 1 週齡およ
び 2 週齢時に子の匹数と一腹体重を測定した。また， 3 週齢（離乳）時に雌親の体重, 子の匹数および一腹 体重を測定した。

統計処理は, 交配したハムスターのうち分婏した雌 親の数を分婏数, 1 匹以上離乳させた雌親の数を離乳 数とし，飼育飼料と交配週齢を要因とした二元配置の $x^{2}$-検定を行った。また，その他の測定形質については 最小二乗法による二元配置の分散分析 [2] を行い, 有 意差の認められた要因について $\mathrm{t}$ 検定を行った。

\section{成 績}

ハムスターの雌親の分婏数および離乳数を Table 2 に，その検定結果を Table 3 に示した。分婏数および 離乳数の両形質において飼育飼料間に統計的に有意な

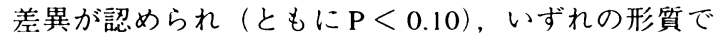
も育成期にZC-2, 繁殖期にMB-1を用いたものが他の 飼料区に比べて匹数が多かった。また，分婏数におい ては雌親の交配週齢に有意差がみられ $(\mathrm{P}<0.05), 12$ 週齢交配区のほうが8週齢交配区に比べて高い繁殖成 績を示した。

分婏時，1，2および 3 週齢時における子の匹数およ び一腹体重の最小二乗平均とその標準誤差を Table 4 に，その検定結果を Table 5 に示した。分婏時におけ 
る産子数および一腹体重では，育成期，繁殖期とも MB-1を給与した区が最も高い值をとり，育成期，繁 殖期とも ZC-2を給与した区が最も低い值となった。 しかし，分娩日からの週齢が進むにつれて育成期に ZC-2, 繁殖期にMB-1 を給与した区が高い成績を示す 傾向にあり，3 週齢時における子の匹数および一腹体 重は, 他の3区に比べて最も高い値を示した。育成期, 繁殖期とも ZC-2 を給与した区では，実験期間を通し て最も低い成績を示す傾向がみられた。雌親の交配週 齢については, 分婏時における産子数および一腹体重 で有意差が認められ，12週齢交配区は8週齢交配区に 比べて高い值を示す傾向にあった。しかし，その後の 週齢において両者の間に統計学的有意差はみられな かった。

交配時, 分婏時および離乳時における雌親の体重の 最小二乗平均とその標準誤差を Table 6 に，その検定 結果をTable 7 に示した。交配時における体重は，育 成期にMB-1を給与した雌が育成期にZC-2 を給与し た雌よりも重い傾向にあり，12週齢で交配した雌にお いてその差が顕著であった。分婏時や離乳時におけ る雌の体重においても同様の傾向が認められた。ま た, 交配後に飼料を切り換えたことによる雌の体重へ の影響は, 育成期にZC-2 を給与した雌の離乳時体重
においてのみ有意差が認められ，交配時にMB-1に切 り換えた区の体重が重くなった。8週齢交配区は12週 齢交配区に比べて交配時から分婏時までの体重の増加 量が大きく, 分婏時から離乳時までの体重の減少量が 小さかった。

\section{考 察}

ハムスターは二腔胃を持ち [5], 草類に対する嗜好 性が高いことなどから [6], 八ムスターの栄養生理学 的な特性に注目した研究が報告されている $[8]$ 。また, これらの特性を反膓動物と比較した報告もみられ，八 ムスターの草食家畜用の実験動物としての期待が高 まっている [11]。

一方, 家畜育種のパイロットアニマルとしての選抜 実験にはマウスが最も頻繁に用いられている。これに 対して, 八ムスターは飼料摂取量が多く,より広い飼 育スペースを必要とするため, 家畜育種学的観点から のパイロットアニマルとしての評価は低く，ハムス ターが家畜育種の実験に用いられた例は少ない [9]。 しかし，ハムスターは粗飼料利用性が高いことから， 主として反䏮家畜用の選抜実験動物としての有用性が 期待される $[11]$ 。本研究はハムスターを選拔育種実験

Table 4. Least-squares means and standard errors of litter traits

\begin{tabular}{|c|c|c|c|c|c|c|c|c|c|}
\hline \multirow{2}{*}{$\begin{array}{l}\text { Age of } \\
\text { (weeks) }\end{array}$} & \multirow{2}{*}{ Feed } & \multicolumn{4}{|c|}{ Litter size } & \multicolumn{4}{|c|}{ Litter weight (g) } \\
\hline & & 0 -week & l-week & 2-week & 3-week & 0-week & 1-week & 2-week & 3 -week \\
\hline \multirow[t]{4}{*}{8} & $\mathrm{ZC} \rightarrow \mathrm{ZC}$ & $7.7 \pm 0.5$ & $7.2 \pm 0.5$ & $6.9 \pm 0.5$ & $5.7 \pm 0.5$ & $21.4 \pm 1.2$ & $52.6 \pm 3.4$ & $102.9 \pm 7.3$ & $168.9 \pm 19.1$ \\
\hline & $\mathrm{ZC} \rightarrow \mathrm{MB}$ & $8.4 \pm 0.4$ & $7.8 \pm 0.4$ & $6.9 \pm 0.4$ & $6.2 \pm 0.4$ & $23.4 \pm 1.0$ & $55.1 \pm 2.8$ & $106.4 \pm 6.2$ & $205.3 \pm 16.0$ \\
\hline & $\mathrm{MB} \rightarrow \mathrm{ZC}$ & $8.3 \pm 0.5$ & $7.9 \pm 0.5$ & $7.4 \pm 0.5$ & $6.0 \pm 0.5$ & $23.2 \pm 1.2$ & $55.8 \pm 3.4$ & $107.6 \pm 7.5$ & $165.7 \pm 19.5$ \\
\hline & $\mathrm{MB} \rightarrow \mathrm{MB}$ & $8.6 \pm 0.5$ & $8.0 \pm 0.5$ & $7.0 \pm 0.5$ & $5.8 \pm 0.5$ & $23.7 \pm 1.2$ & $57.0 \pm 3.4$ & $101.8 \pm 7.5$ & $175.8 \pm 19.4$ \\
\hline \multirow[t]{4}{*}{12} & $\overline{\mathrm{ZC}} \overline{\mathrm{ZC}}$ & $8 . \overline{7} \pm \overline{0.4}$ & $7 . \overline{5 \pm 0.5}$ & $6 . \overline{5 \pm 0.4}$ & $5 . \overline{4 \pm} \overline{0.5}$ & $\overline{23} . \overline{4 \pm 1} .0$ & $55 . \overline{2.9}$ & $90.8 \pm 6.4$ & $\overline{147.9} \pm \overline{16} . \overline{6}$ \\
\hline & $\mathrm{ZC} \rightarrow \mathrm{MB}$ & $9.0 \pm 0.4$ & $8.1 \pm 0.4$ & $7.7 \pm 0.4$ & $6.8 \pm 0.4$ & $24.4 \pm 1.0$ & $59.2 \pm 2.8$ & $115.2 \pm 6.2$ & $224.5 \pm 16.2$ \\
\hline & $\mathrm{MB} \rightarrow \mathrm{ZC}$ & $8.9 \pm 0.5$ & $7.7 \pm 0.5$ & $6.7 \pm 0.5$ & $5.5 \pm 0.5$ & $24.9 \pm 1.2$ & $56.0 \pm 3.4$ & $98.5 \pm 7.4$ & $165.6 \pm 19.2$ \\
\hline & $\mathrm{MB} \rightarrow \mathrm{MB}$ & $9.8 \pm 0.5$ & $8.3 \pm 0.5$ & $6.9 \pm 0.5$ & $5.7 \pm 0.5$ & $25.8 \pm 1.2$ & $58.4 \pm 3.3$ & $96.8 \pm 7.5$ & $166.0 \pm 18.8$ \\
\hline
\end{tabular}

Table 5. The level of significance for linear contrasts of litter traits

\begin{tabular}{|c|c|c|c|c|c|c|c|c|}
\hline \multirow{2}{*}{ Source } & \multicolumn{4}{|c|}{ Litter size } & \multicolumn{4}{|c|}{ Litter weight } \\
\hline & 0 -week & 1-week & 2-week & 3-week & 0 -week & 1-week & 2-week & 3-week \\
\hline $\mathrm{ZC} \rightarrow \mathrm{ZC}: \mathrm{ZC} \rightarrow \mathrm{MB}$ & & & & $*$ & & & $*$ & $* *$ \\
\hline $\mathrm{ZC} \rightarrow \mathrm{ZC}: \mathrm{MB} \rightarrow \mathrm{ZC}$ & & & & & & & & \\
\hline $\mathrm{ZC} \rightarrow \mathrm{ZC}: \mathrm{MB} \rightarrow \mathrm{MB}$ & $*$ & + & & & $*$ & & & \\
\hline $\mathrm{ZC} \rightarrow \mathrm{MB}: \mathrm{MB} \rightarrow \mathrm{ZC}$ & & & & & & & & $*$ \\
\hline $\mathrm{ZC} \rightarrow \mathrm{MB}: \mathrm{MB} \rightarrow \mathrm{MB}$ & & & & + & & & + & $* *$ \\
\hline $\mathrm{MB} \rightarrow \mathrm{ZC}: \mathrm{MB} \rightarrow \mathrm{MB}$ & & & & & & & & \\
\hline 8-week : 12-week & $*$ & & & & $*$ & & & \\
\hline
\end{tabular}

$+: \mathrm{P}<0.10, *: \mathrm{P}<0.05, * *: \mathrm{P}<0.01$ 
Table 6. Least-squares means and standard errors of body weights of dams

\begin{tabular}{|c|c|c|c|c|}
\hline \multirow{2}{*}{$\begin{array}{l}\text { Age of } \\
\text { mating } \\
\text { (weeks) }\end{array}$} & \multirow{2}{*}{ Feed } & \multicolumn{3}{|c|}{ Body weight of dam (g) } \\
\hline & & Mating & Birth & Weaning \\
\hline \multirow[t]{4}{*}{8} & $\mathrm{ZC} \rightarrow \mathrm{ZC}$ & $81.7 \pm 1.9$ & $102.4 \pm 1.9$ & $93.6 \pm 2.0$ \\
\hline & $\mathrm{ZC} \rightarrow \mathrm{MB}$ & $82.2 \pm 1.6$ & $103.5 \pm 1.6$ & $95.5 \pm 1.7$ \\
\hline & $\mathrm{MB} \rightarrow \mathrm{ZC}$ & $85.8 \pm 1.9$ & $106.6 \pm 2.0$ & $97.7 \pm 2.1$ \\
\hline & $\mathrm{MB} \rightarrow \mathrm{MB}$ & $83.5 \pm 1.9$ & $105.1 \pm 1.9$ & $97.0 \pm 2.1$ \\
\hline \multirow[t]{4}{*}{$\overline{12}$} & $\overline{\mathrm{ZC}} \rightarrow \overline{\mathrm{ZC}}$ & $\overline{105.0 \pm} \overline{1.6}$ & $\overline{113.7 \pm \overline{1.7}}$ & $93 . \overline{5} \pm 1.8$ \\
\hline & $\mathrm{ZC} \rightarrow \mathrm{MB}$ & $102.9 \pm 1.6$ & $113.7 \pm 1.6$ & $99.5 \pm 1.7$ \\
\hline & $\mathrm{MB} \rightarrow \mathrm{ZC}$ & $110.0 \pm 1.9$ & $122.4 \pm 1.9$ & $104.9 \pm 2.0$ \\
\hline & $\mathrm{MB} \rightarrow \mathrm{MB}$ & $109.1 \pm 1.9$ & $116.4 \pm 1.9$ & $100.1 \pm 2.0$ \\
\hline
\end{tabular}

Table 7. The level of significance for linear contrasts of body weights of dams

\begin{tabular}{lccc}
\hline \multirow{2}{*}{ Source } & \multicolumn{3}{c}{ Body weight of dam } \\
\cline { 2 - 4 } & Mating & Birth & Weaning \\
\hline $\mathrm{ZC} \rightarrow \mathrm{ZC}: \mathrm{ZC} \rightarrow \mathrm{MB}$ & & $* *$ & $*$ \\
$\mathrm{ZC} \rightarrow \mathrm{ZC}: \mathrm{MB} \rightarrow \mathrm{ZC}$ & + & $*$ & $*$ \\
$\mathrm{ZC} \rightarrow \mathrm{ZC}: \mathrm{MB} \rightarrow \mathrm{MB}$ & & & + \\
$\mathrm{ZC} \rightarrow \mathrm{MB}: \mathrm{MB} \rightarrow \mathrm{ZC}$ & $*$ & $* *$ & \\
$\mathrm{ZC} \rightarrow \mathrm{MB}: \mathrm{MB} \rightarrow \mathrm{MB}$ & $*$ & & \\
$\mathrm{MB} \rightarrow \mathrm{ZC}: \mathrm{MB} \rightarrow \mathrm{MB}$ & & & \\
$8-$ week $: 12-$ week & $*$ & $*$ & $* *$ \\
\hline$+: \mathrm{P}<0.10, * * \mathrm{P}<0.05, * *: \mathrm{P}<0.01$ & &
\end{tabular}

に用いる場合の飼育飼料について検討したものであ る。

本実験の結果から，育成期にZC-2 を給与し，繁殖 期にMB-1を給与した区が, 雌親の分婏数, 離乳数, 3 週齢時における子の匹数および一腹体重において, 他 の3区に比べて最も高い成績を示した。この原因とし て，育成期にMB-1を給与した場合，栄養の過剩椇取 による繁殖障害が考えられる。一方，繁殖期にZC-2 を給与した場合には, 栄養不足による受胎率の低下や 泌乳量の減少などが考えられる。また，ハムスターを 高稚維飼料で育成した場合, 市販のアウス・ラット用 飼料で育成した場合に比べて前胃および盲腸の重量が 2４倍に増加したという報告がある [7]。このことか ら，育成期にZC-2を給与したハムスターは消化管の 発育が高まることによって繁殖期における消化能力が 高く,これが泌乳能力に影響を与えた可能性が考えら れる。事実, 育成期に ZC-2 を給与し, 繁殖期に MB1を給与した区の雌親は分婏から離乳までの体重減少 が最も小さく，子の一腹体重が最も重かった。しかし 本実験では, 飼料椇取量の測定, 消化試験, 体構成成 分分析等を実施していないため,これらの考察は仮説 の域を出ない。
交配週齢では, 雌親の分婏数, 分婏時における産子 数と一腹体重において有意差が認められこれらの形 質に関して 12 週齢交配区は 8 週龄交配区に比べて高 い成績を示した。しかし, 最も高い成績を示した飼料 区（育成期: ZC-2, 繁殖期: MB-1）内では交配週齢に よる雌親の分婏数に差がみられず，また離乳時におけ る子の匹数や一腹体重にも差がみられなかった。した がって,多くの離乳子数を得て選抜差を高めるために は, 8 週齢または 12 週齢のいずれで交配しても差はな いと考えられる。たたし，育種実験において世代間隔 を短くするという観点からは, 12 週齢交配よりも8週 齢交配のほうが望ましいといえる。

本研究結果から, ハムスターの育成期には比較的高 緎維質の飼料を給与し, 繁殖期に繁殖用飼料に切り換 えることによって高い繁殖成績をもたらすことが明ら かとなった。従来, 実験動物用飼料は配合割合を一定 にし，生涯にわたり栄養レベルを一定に保つことが必 要条件とされてきた。しかし，市販の高タンパク質， 高エネルギー飼料の長期給与は肥満等の誘発につなが ることが明らかとなっており[3]，この意味からも適 正な実験動物用飼料を検討する必要がある。本実験で 用いた飼料は市販の 2 飼料のみであったが, 繁殖成績 をさらに高めるためにはより優れた飼料の組み合わせ が必要であると考えられる。より適正な飼料の給与方 法や飼料の組み合わせについては今後の検討課題とな ろう。

\section{要 約}

シリアンハムスターを選抜実験に用いるため, 給与 飼料および交配週齢が受胎率や離乳子数などの繁殖成 績に及ほす影響について検討した。雌 240 匹を2群に 分け、1群には草食動物用飼料 ZC-2, 他の1群には繁 殖用飼料 MB-1 を給与して育成した (育成期)。交配 時に各群をさらに2 群に分け，1群は育成期と同一飼 
料，他のI群は飼料を変えて繁殖させた(繁殖期)。交 配は各群の半数を 8 週齢, 残りの半数を 12 週齢で行っ た。育成期にZC- 2 を給与し, 繁殖期にMB-1を給与し た区が, 雌親の分娩数, 離乳数，3週龄時における子 の匹数および一腹体重において有意に高い值を示した $(\mathrm{P}<0.01)$ 。12 週齢交配区は 8 週跲交配区に比べて, 雌親の分婏数, 分婏時における産子数と一腹体重にお いて有意に高い值を示した。しかし，3週齢における 子の匹数や一腹体重には差がみられなかった。以上の 結果から,ハムスターの育成期には比較的高䋐維質の 飼料を給与し, 繁殖期に繁殖用飼料に切り換えること によって高い繁殖成績が得られることが明らかとなっ た。

\section{文 献}

[1] Furukawa, T., Tanaka, H. and Awata, T. (1992). Selection experiment in the golden hamster for testis size and correlated responses in female reproductive traits. Proc. 3rd World Congr. Genet. Appl. Livest. Prod.. 11, 203-208.

[2] Harvey, W.R.(1985). User's guide for LSMLMW. Ohio State Univ., Columbus.
［3］猪 貴義 (1982). 育種. pp.66-126, 栄養と飼料. pp.171-196, 実験動物学, 養賢堂, 東京.

[4] Kent. G.C. (1968). Physiology of Reproduction. In: The golden hamster, pp.119-138, Hoffman. R.A., Robinson, P.F. and Magalhaes, H. (eds.), Iowa State Univ., Ames.

[5] Magalhaes, H. (1968). Gross Anatomy. In: The golden hamster, pp.91-110, Hoffman, R.A., Robinson, P.F. and Magalhaes. H. (eds.), Iowa State Univ., Ames.

[6] Manda, T. and Takano, N. (1976). Growth response of golden hamster to diets having different levels of for ages. J. Japan Grassl. Sci., 22, 46-51.

[7] 萬田富治 (1979). 八ムス夕一の栄養生理と粗飼料の 利用性. 栄養生理研報, 23、111-128.

[8] 村井 勝 (1986). 八ムス夕一の栄養生理的特性. 草 食家畜用実騃動物，11，50-62.

[9] 佐藤正寛・古川 力・西田 朗 (1991). 多形質のア ニマルモデルによるゴールデンハムスターの繁殖能 力の選抜. 日畜会報, 62,771-773.

[10] 篠原 久. 亘場猛夫・水間 豊 (1989). 䋐維質飼料 の利用特性に関する実験小動物種間比較。日草誌, 35, $247-253$.

[11] 篠原 久(1986). 草食家畜用実騃動物としてのハムス 夕一の選抜育種. 草食家音用実験動物，11，39-49. 